Polymer Journal, Vol. 38, No. 10, pp. 1068-1073 (2006)

(C) 2006 The Society of Polymer Science, Japan

\title{
Preparation of Fully Aromatic Polysilarylenesiloxanes by Melt Polycondensation and Their Thermal Properties
}

\author{
Hitoshi Ito, ${ }^{1, \dagger}$ Eiichi AkiYama, ${ }^{2}$ Yu Nagase, ${ }^{3}$ Akiko Yamamoto, ${ }^{3}$ and Saburo FukUI ${ }^{3}$ \\ ${ }^{1}$ Applied Chemistry Lab., Ebara Research Co., Ltd, 4-2-1 Honfujisawa, Fujisawa 251-8502, Japan \\ ${ }^{2}$ Sagami Chemical Research Center, 2743-1 Hayakawa, Ayase 252-1193, Japan \\ ${ }^{3}$ Department of Applied Chemistry, School of Engineering, Tokai University, \\ 1117 Kitakaname, Hiratsuka 259-1292, Japan
}

(Received April 5, 2006; Accepted July 28, 2006; Published September 7, 2006)

\begin{abstract}
The melt polycondensation of the two kinds of the bis(hydroxydiphenylsilyl)arylene monomers, 1,4bis(hydroxydiphenylsilyl)benzene and 4,4'-bis(hydroxydiphenylsilyl)biphenyl, was investigated. The thermal properties of the obtained polymers were studied by using a thermogravimetry analysis, a differential scanning calorimetry and a thermomechanical analysis. The IR spectra and the XRD patterns of the polymers indicated that the melt polycondensation occurred in the temperature range from $290^{\circ} \mathrm{C}$ to $400^{\circ} \mathrm{C}$. The $5 \%$ weight loss temperatures of the polymers synthesized at above $350^{\circ} \mathrm{C}$ was around or over $500^{\circ} \mathrm{C}$, so that these polymers exhibited high thermal stability. All the polymers which were obtained by the melt polycondensation of 1,4-bis(hydroxydiphenylsilyl)benzene exhibited the glass transition temperatures. On the contrary, the polymers obtained from 4,4'-bis(hydroxydiphenylsilyl)biphenyl at above $350^{\circ} \mathrm{C}$ showed no phase transitions in the DSC measurements. From the analysis of the volatile compounds generated during the melt polycondensation of $4,4^{\prime}$-bis(hydroxydiphenylsilyl)biphenyl by using a gas chromatograph mass spectrometry and the comparison of the ${ }^{13} \mathrm{C} \mathrm{CP}$-MAS NMR spectra of the polymers, it was shown that the cross-linking reaction resulting from the thermal decomposition of the monomers and the produced oligomers took place simultaneously. It was revealed that the melt polycondensation and simultaneous cross-linking reaction were effective to obtain the polysilarylenesiloxanes which have high thermal degradation temperature and high thermomechanical stability. [doi:10.1295/polymj.PJ2006004]

KEY WORDS Polysilarylenesiloxane / Melt Polycondensation / Thermal Stability / Glass Transition / Thermomechanical Stability /
\end{abstract}

Polysilarylenesiloxanes ${ }^{1,2}$ and their copolymers ${ }^{2-18}$ have been investigated as high temperature elastomers. The common characteristics of these polymers are their high thermal degradation temperatures $\left(T_{\mathrm{d}}\right.$ 's) and low glass transition temperatures $\left(T_{\mathrm{g}}\right.$ 's), which are attributed to their flexible tetramethyldisiloxane units in the main chain. ${ }^{2-18}$ These characteristics are desirable for an elastomer, and are, however, undesirable for the heat-resistant materials such as a high-temperature coating and a low dielectric insulation material in semiconductor devices because the thermomechanical stability of these polymers is not enough at high temperature. Therefore, polysilarylenesiloxanes and their copolymers have never been used nothing but elastomers. If a new type of polysilarylenesiloxane with a high $T_{\mathrm{g}}$ is obtained, it is possible that the polysilarylenesiloxane is applied to such heat-resistant materials.

On the other hand, we reported that the fully aromatic polysilarylenesiloxanes, which were synthesized via the solution polymerization, poly(tetraphenyl- $p$-silphenylenesiloxane) (polyPS) and poly(tetraphenyl- $p, p^{\prime}$-silbiphenylenesiloxane) (polyBS), showed no weight loss in air below $500{ }^{\circ} \mathrm{C}$ and had high melt-

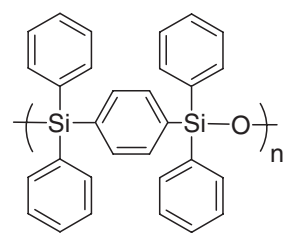

polyPS

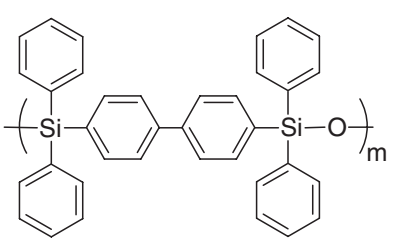

polyBS
Figure 1. The chemical structures of polyPS and polyBS.

ing temperatures $\left(T_{\mathrm{m}}\right.$ 's) of $323^{\circ} \mathrm{C}$ and $391^{\circ} \mathrm{C}$, respectively $^{19}$ (Figure 1). It was revealed that these polymers were candidates for new heat-resistant materials. Unfortunately, these polymers were obtained as insoluble powder, therefore, these polymers had a drawback to a practical use. In our previous report, ${ }^{19}$ an interesting phenomenon was also observed, that is, the condensation reaction between the silanols of the bis(hydroxydiphenylsilyl)arylene monomers above their $T_{\mathrm{m}}$ was done. This phenomenon was not observed in the heating process of the bis(hydroxydimethylsilyl)arylene monomers because the monomers were decomposed or vaporized. The condensation reaction of the silanols, that is, the melt polycondensa-

${ }^{\dagger}$ To whom correspondence should be addressed (Tel: +81-466-83-7022, Fax: +81-466-81-7220, E-mail: itoh.hitoshi@er.ebara.com). 
tion was a characteristic phenomenon which occurred only in the case of bis(hydroxydiphenylsilyl)arylene monomers. H. N. Beck et al., had also noted the condensation of the silanols occurred during the prolonged heating of the monomers ${ }^{20}$ although they did not investigated the phenomenon in detail. In addition, the characterizations and thermal properties of the products obtained by this reaction have never been studied. This convenient procedure has a possibility to get rid of the disadvantage of the fully aromatic polysilarylenesiloxanes and to apply these polymers to a practical use.

In this study, the melt polycondensation of the two kinds of the monomers, 1,4-bis(hydroxydiphenylsilyl)benzene and 4,4'-bis(hydroxydiphenylsilyl)biphenyl, which were synthesized according to the literature, ${ }^{19}$ were investigated. The thermal properties of the obtained polymers were studied by using a thermogravimetry analysis (TGA), a differential scanning calorimetry (DSC) and a thermomechanical analysis (TMA). To investigate the process of the melt polycondensation in detail, the volatile compounds generated during the reactions were analyzed by a gas chromatograph mass spectrometry (GC-MS), and ${ }^{13} \mathrm{C} \mathrm{CP}-$ MAS NMR spectra of the polymers were obtained. From these results, the mechanism of the melt polycondensation process and the influence of the polymer main chain structures on their thermal properties will be discussed.

\section{EXPERIMENTAL}

\section{Materials}

The two kinds of the monomers, 1,4-bis(hydroxydiphenylsilyl)benzene (1a) and 4,4'-bis(hydroxydiphenylsilyl)biphenyl (1b) were synthesized according to our previous report. ${ }^{19}$ The fully aromatic polysilarylenesiloxanes were also synthesized by the solution polymerization according to our previous report. ${ }^{19}$

\section{Melt Polycondensation}

Each monomer of $\mathbf{1}(\mathbf{a}, \mathbf{b})(50 \mathrm{mg})$ mounted on a glass plate was heated for $10 \mathrm{~min}\left(60 \mathrm{~min}\right.$ for $\left.\mathbf{3}^{\prime}(\mathbf{a}, \mathbf{b})\right)$ with a heater instrumented a thermo-controller at $250^{\circ} \mathrm{C}(\mathbf{2}(\mathbf{a}, \mathbf{b})), 290^{\circ} \mathrm{C}\left(\mathbf{3}(\mathbf{a}, \mathbf{b})\right.$ and $\left.\mathbf{3}^{\prime}(\mathbf{a}, \mathbf{b})\right)$, $350^{\circ} \mathrm{C}(4(\mathbf{a}, \mathbf{b}))$ and $400{ }^{\circ} \mathrm{C}(\mathbf{5}(\mathbf{a}, \mathbf{b}))$, respectively (Scheme 1).

\section{Characterizations}

IR spectra were measured with a PerkinElmer PARAGON FT-IR. X-Ray diffraction (XRD) patterns by the powder method were collected on a RIGAKU RINT 2000 Diffractometer using $\mathrm{CuK} \alpha$ radiation. The samples were annealed for $1 \mathrm{~h}$ at $160^{\circ} \mathrm{C}$ before measurements. The ${ }^{13} \mathrm{C}$ CP-MAS NMR spectra (100.6

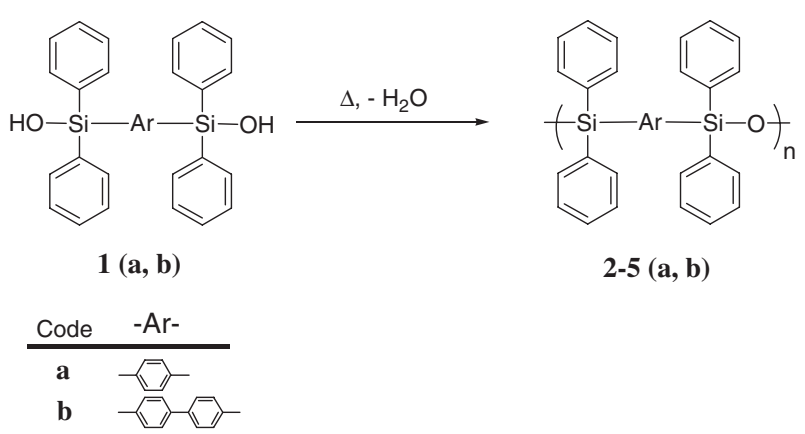

Scheme 1. The melt polycondensation.

MHz) were obtained on a Bruker Biospin AVANCE DRX 400 Spectrometer $(400 \mathrm{MHz})$ at a spin rate of $5 \mathrm{kHz}$. A contact time was $3 \mathrm{~ms}$ and 1,000 scans were taken in each sample.

\section{Thermal Analyses}

TGA was performed by using a Shimadzu DTG $60 \mathrm{~A}$ at a heating rate of $10^{\circ} \mathrm{C} \mathrm{min}^{-1}$ with an air flow rate of $50 \mathrm{~mL} \mathrm{~min}^{-1}$ in order to investigate the thermal degradation behavior. DSC was conducted by using a Shimadzu DSC 60 at a heating rate of $10^{\circ} \mathrm{C} \mathrm{min}^{-1}$ with a nitrogen flow rate of $50 \mathrm{~mL} \mathrm{~min}^{-1}$ in order to determine $T_{\mathrm{g}}$ and/or $T_{\mathrm{m}}$. The samples were annealed for $1 \mathrm{~h}$ at $160^{\circ} \mathrm{C}$ before measurements. TMA was performed in order to determine softening point $\left(T_{\mathrm{S}}\right)$ on a Shimadzu TMA 60 using a penetration probe of $0.5 \mathrm{~mm}$ diameter under constantly applied load of $50 \mathrm{~g}$, at a heating rate of $10^{\circ} \mathrm{C} \mathrm{min}^{-1}$ with a nitrogen flow rate of $50 \mathrm{~mL} \mathrm{~min}^{-1}$. The $T_{\mathrm{s}}$ 's were determined as the intersection of the tangents of the two linear segments in TMA curves.

\section{The Analysis of the Volatile Compounds}

Each monomer of $\mathbf{1}(\mathbf{a}, \mathbf{b})(100 \mathrm{mg})$ was placed in a glass tube oven and heated at a heating rate of $10{ }^{\circ} \mathrm{C} \mathrm{min}^{-1}$ up to $300^{\circ} \mathrm{C}$ and hold for $10 \mathrm{~min}$. The inner pressure of the glass vessel was kept constant at $65 \mathrm{kPa}$. The volatile compounds were collected in the vessel cooled with the frozen $\mathrm{CO}_{2}$, then dissolved in the tetrahydrofuran solution. Then the same sample was heated up to $350{ }^{\circ} \mathrm{C}$ and $400^{\circ} \mathrm{C}$, and hold for $10 \mathrm{~min}$ at each temperature. The volatile compounds were collected at each temperature in the same way. The mass of the compounds in the solution were analyzed by using a HP-5890 (gas chromatograph) and HP-5971 (mass selective detector).

\section{RESULTS AND DISCUSSION}

\section{Synthesis and Thermal Properties of the Polymers}

All the obtained polymers were fragile thin solid films, and were partially dissolved in common sol- 


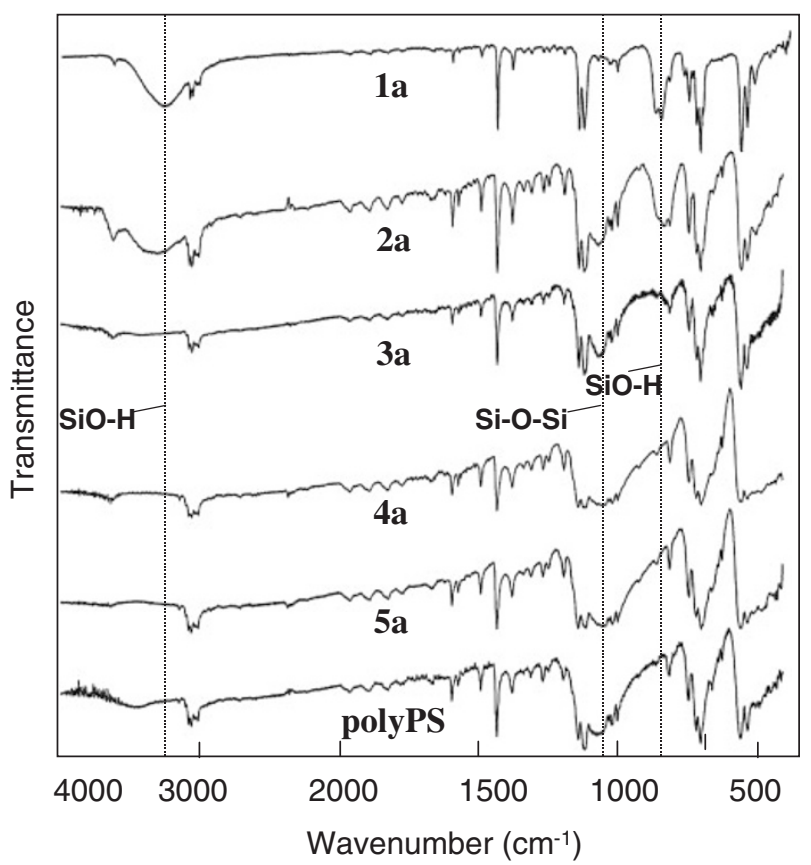

Figure 2. The IR spectra of $\mathbf{1 a}$ (monomer), 2a $\left(250^{\circ} \mathrm{C}\right), \mathbf{3 a}$ $\left(290^{\circ} \mathrm{C}\right), \mathbf{4 a}\left(350^{\circ} \mathrm{C}\right), \mathbf{5 a}\left(400^{\circ} \mathrm{C}\right)$ and polyPS.

vents such as tetrahydrofuran and chloroform. The IR spectra of 1-5a and polyPS are shown in Figure 2. The absorption peak intensities at $3200 \mathrm{~cm}^{-1}$ arising from the silanol $\mathrm{O}-\mathrm{H}$ stretching vibration and at $850 \mathrm{~cm}^{-1}$ arising from the silanol $\mathrm{Si}-\mathrm{O}$ stretching vibration decreased with increasing of the melt polycondensation temperature. On the contrary, new broad absorption peaks were observed near at $1060 \mathrm{~cm}^{-1}$ arising from the $\mathrm{Si}-\mathrm{O}-\mathrm{Si}$ bond, and the peak intensities increased with the increase of the temperature. However, the peak intensities of $\mathbf{4 a}$ was almost the same with that of 5a. The IR spectra of 3-5a almost coincided with that of polyPS. From these results, the melt polycondensation occurred by the heating process. In the IR spectra of $\mathbf{2 - 5} \mathbf{b}$, the similar results were observed as that of $\mathbf{2 - 5 a}$.

The XRD patterns of $\mathbf{1 - 5} \mathbf{a}$ and polyPS are shown in Figure 3. The diffraction peaks of $\mathbf{2 a}$ contained the peaks of the monomer. The peak intensities of $\mathbf{2 a}$ at around $2 \theta=8^{\circ}, 16^{\circ}$ and $22^{\circ}$ were larger than that of 1a. This may be caused by the recrystallization of the monomer because the monomer was melted in the heating process. The diffraction peaks of $\mathbf{3 a}$ and 4a almost agreed with that of polyPS. The XRD measurements also supported the melt polycondensation. However, 5a was amorphous solid because only two broad halos were observed at around $2 \theta=10^{\circ}$ and $20^{\circ}$ in the pattern. The XRD patterns of $\mathbf{2 - 5} \mathbf{b}$ showed the similar tendency as that of 2-5a.

The TG curves of 1a, 3-5a and polyPS are shown in Figure 4. In the chart of 3a, about $5 \sim 6 \%$ weight loss was observed similarly to the monomer in the

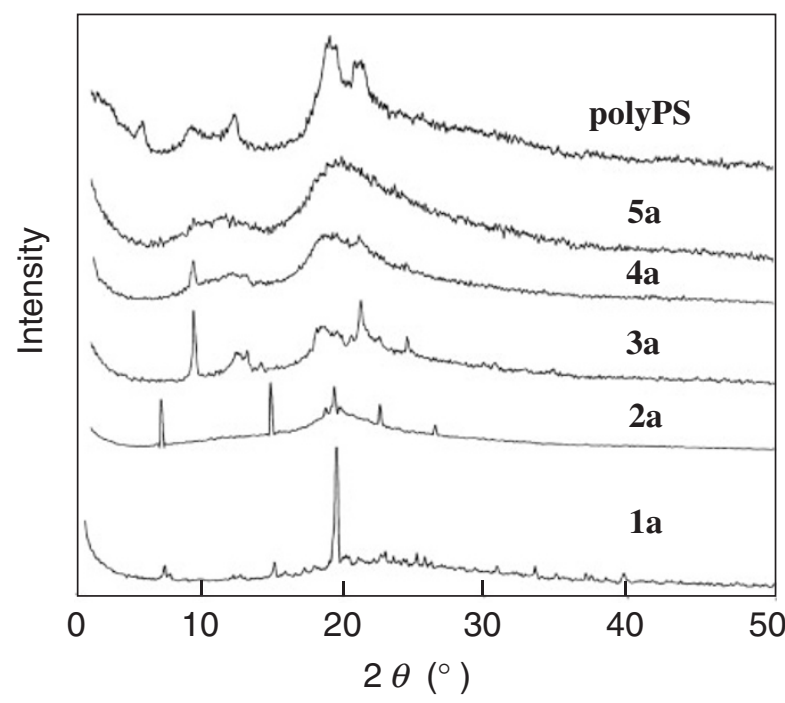

Figure 3. The $\mathrm{XRD}$ patterns of $\mathbf{1 a}$ (monomer), 2a $\left(250^{\circ} \mathrm{C}\right)$, 3a $\left(290^{\circ} \mathrm{C}\right), 4 \mathbf{a}\left(350^{\circ} \mathrm{C}\right)$, 5a $\left(400^{\circ} \mathrm{C}\right)$ and polyPS.

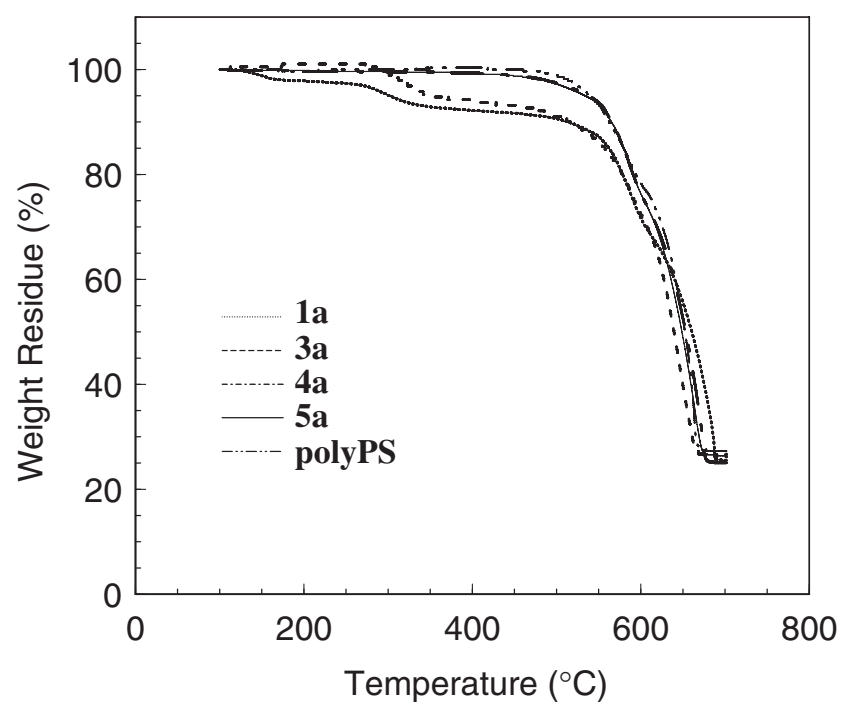

Figure 4. The TGA curves of $\mathbf{1 a}$ (monomer), 3a $\left(290^{\circ} \mathrm{C}\right), \mathbf{4 a}$ $\left(350^{\circ} \mathrm{C}\right), \mathbf{5 a}\left(400^{\circ} \mathrm{C}\right)$ and polyPS.

temperature range from $250{ }^{\circ} \mathrm{C}$ to $400^{\circ} \mathrm{C}$. This weight loss was caused by the melt polycondensation and/or thermal decomposition of the unreacted monomers and the produced oligomers. On the contrary, in the TG curves of $\mathbf{4 a}$ and $\mathbf{5 a}$, no weight loss was observed in this temperature range. These polymers exhibited good thermal stability as well as polyPS. The 5\% weight loss temperatures $\left(T_{\mathrm{d} 5}\right.$ 's) of the polymers are summarized in Table I. $\mathbf{4 b}$ and $\mathbf{5 b}$ also showed high thermal stability. From these results, the high heatresistant films could be prepared via the melt polycondensation of the convenient procedure.

The DSC curves of a-series and $\mathbf{b}$-series are shown in Figures 5 and 6, respectively. The $T_{\mathrm{g}}$ 's were observed in the DSC curves except for $\mathbf{4 b}$ and $\mathbf{5 b}$. In the chart of $\mathbf{3 b}$, two baseline shifts were observed at 
Fully Aromatic Polysilarylenesiloxanes Prepared by Melt Polycondensation

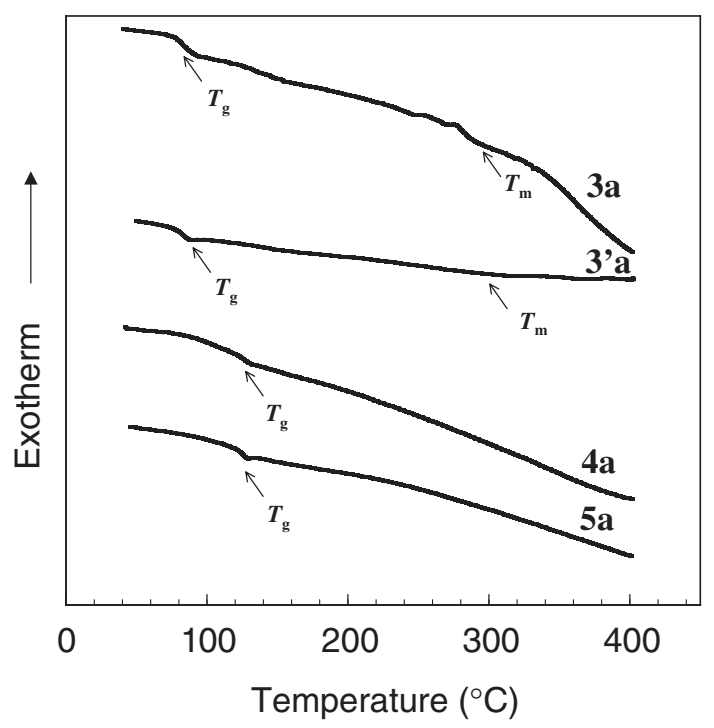

Figure 5. The DSC curves of 3a $\left(290{ }^{\circ} \mathrm{C}\right), 3^{\prime} \mathbf{a}\left(290^{\circ} \mathrm{C}\right.$, $60 \mathrm{~min}), \mathbf{4 a}\left(350^{\circ} \mathrm{C}\right)$ and $\mathbf{5 a}\left(400^{\circ} \mathrm{C}\right)$.

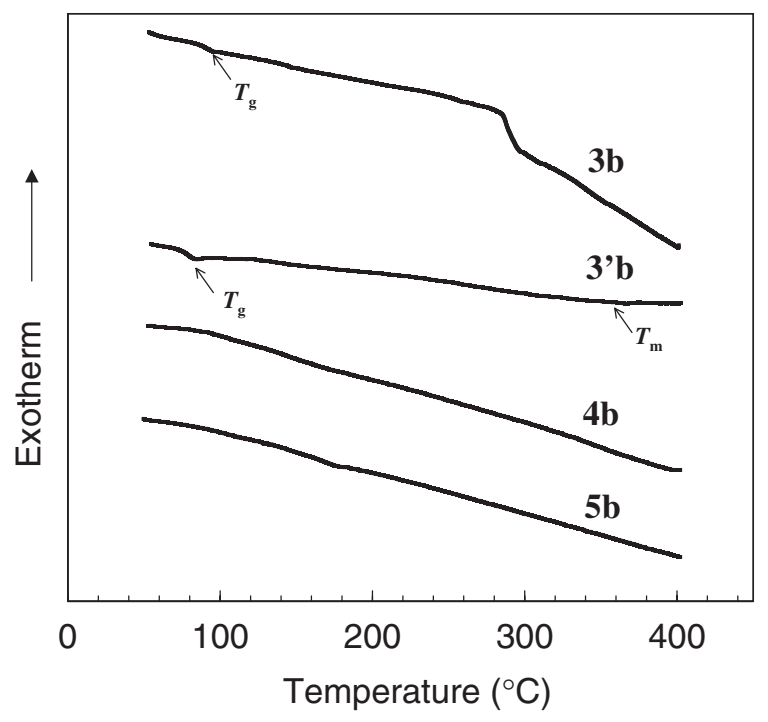

Figure 6. The DSC curves of $\mathbf{3 b}\left(290^{\circ} \mathrm{C}\right), \mathbf{3}^{\prime} \mathbf{b}\left(290^{\circ} \mathrm{C}\right.$, $60 \mathrm{~min}), \mathbf{4 b}\left(350^{\circ} \mathrm{C}\right)$ and $\mathbf{5 b}\left(400^{\circ} \mathrm{C}\right)$.

around $94^{\circ} \mathrm{C}$ and $290^{\circ} \mathrm{C}$. Since the $T_{\mathrm{s}}$ of $\mathbf{3 b}$ was $87^{\circ} \mathrm{C}$ as shown in Table I, the baseline shift at around $94^{\circ} \mathrm{C}$ would be caused by the glass transition. The other baseline sift at $290^{\circ} \mathrm{C}$ would be arising from the condensation reaction of the unreacted silanols, because this baseline shift was not observed in the DSC chart of the sample heated at $290^{\circ} \mathrm{C}$ for $60 \mathrm{~min}\left(\mathbf{3}^{\prime} \mathbf{b}\right)$. The broad and small endothermic peaks related to the $T_{\mathrm{m}}$ 's were observed in the chart of $\mathbf{3 a}, \mathbf{3}^{\prime} \mathbf{a}$ and $\mathbf{3 b}$. These peaks would support the melt polycondensation, but these peaks were not clear, and the endothermic peaks related to the $T_{\mathrm{m}}$ was not observed in the charts of the other polymers. These results indicated that the polymers obtained by the melt polycondensation would contain the large amorphous part. In the
Table I. Thermal properties of the obtained polymers

\begin{tabular}{cccccc}
\hline Polymer & $\begin{array}{c}T_{\mathrm{m}}{ }^{\mathrm{a}} \\
\left({ }^{\circ} \mathrm{C}\right)\end{array}$ & $\begin{array}{c}\Delta H_{\mathrm{m}}{ }^{\mathrm{a}} \\
\left(\mathrm{J} \cdot \mathrm{g}^{-1}\right)\end{array}$ & $\begin{array}{c}T_{\mathrm{g}}{ }^{\mathrm{a}} \\
\left({ }^{\circ} \mathrm{C}\right)\end{array}$ & $\begin{array}{c}T_{\mathrm{s}}^{\mathrm{c}} \\
\left({ }^{\circ} \mathrm{C}\right)\end{array}$ & $\begin{array}{c}T_{\mathrm{d} 5}{ }^{\mathrm{d}} \\
\left({ }^{\circ} \mathrm{C}\right)\end{array}$ \\
\hline $\mathbf{3 a}$ & 294 & -3.43 & 85.4 & 83.0 & 351 \\
$\mathbf{4 a}$ & - & - & 130 & 120 & 540 \\
$\mathbf{5 a}$ & - & - & 127 & 121 & 533 \\
polyPS & $(323)^{\mathrm{b}}$ & $(-1.59)^{\mathrm{b}}$ & - & - & 539 \\
\hline $\mathbf{3 b}$ & - & - & 94 & 87.0 & 341 \\
$\mathbf{4 b}$ & - & - & - & 129 & 487 \\
$\mathbf{5 b}$ & - & - & - & 170 & 528 \\
polyBS & 391 & 14.1 & - & - & 500 \\
\hline
\end{tabular}

${ }^{\text {a }}$ The melting point, the enthalpy change and the glass transition temperature determined by DSC on the first heating scan. ${ }^{\text {b}}$ The melting point and the enthalpy change determined by DSC on the second heating scan. ${ }^{\mathrm{c}}$ The softening point determined by TMA. ${ }^{\mathrm{d}}$ The $5 \%$ weight loss temperature determined from a TG curve.

DSC charts of $\mathbf{4 - 5} \mathbf{b}$, no obvious phase transitions were observed different from the charts of 4-5a. According to the TMA measurements of $\mathbf{4 b}$ and $\mathbf{5 b}$, the $T_{\mathrm{s}}$ 's were observed at $129^{\circ} \mathrm{C}$ and $170^{\circ} \mathrm{C}$, respectively as shown in the Table I. These polymers would have $T_{\mathrm{g}}$ 's around their $T_{\mathrm{s}}$ 's because the $T_{\mathrm{g}}$ 's of the other polymers were close to their $T_{\mathrm{s}}$ 's. Considering the obvious $T_{\mathrm{g}}$ was not observed in their charts, the changes of the heat capacitance of $\mathbf{4 b}$ and $\mathbf{5 b}$ arising from the glass transition were smaller than those of the other polymers, and the polymer chain motion would be restricted in the case of $\mathbf{4 b}$ and $\mathbf{5 b}$. The mechanism of this phenomenon is discussed in the next paragraph.

\section{The Mechanism of the Melt Polycondensation}

The melt polycondensation process was investigated in detail to reveal the influence of the main chain structure on the thermal properties of the obtained polymers, that is, to illuminate the difference of the thermal properties between 4-5a and 4-5b. As shown in Figure 4, 1a showed about $7 \%$ weight loss in temperature range $250-400^{\circ} \mathrm{C}$, on the other hand, $\mathbf{1 b}$ showed about $25 \%$ weight loss at $200-400{ }^{\circ} \mathrm{C} .{ }^{19}$ The theoretical weight losses of $\mathbf{1 a}$ and $\mathbf{1 b}$ caused by the condensation reaction with silanols were $3.8 \%$ and $3.3 \%$, respectively. The weight losses of a-series were slightly larger than the theoretical value, and those of b-series were fairly larger than it. These large weight losses could not be explained by the only dehydration and would suggest the other reaction occurred simultaneously.

The volatile compounds generated during the melt polycondensation were collected in a glass vessel cooled with the frozen $\mathrm{CO}_{2}$ to analyze their mass by a GC-MS. As a result, only a peak was detected in the gas chromatogram of the volatile compound dur- 


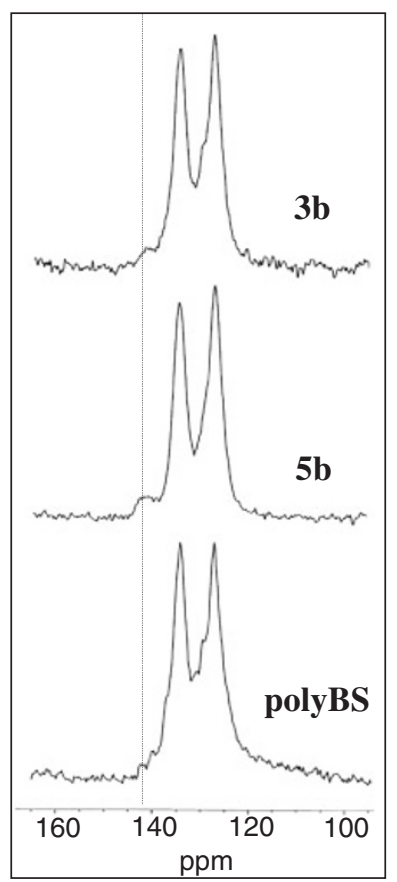

Figure 7. The ${ }^{13} \mathrm{C}$ CP-MAS NMR spectra of $\mathbf{3 b}\left(290^{\circ} \mathrm{C}\right), \mathbf{5 b}$ $\left(400{ }^{\circ} \mathrm{C}\right)$ and polyBS.

ing heating process of $\mathbf{1 a}$ in all the conditions. The molecular ion of the peak was $m / z=276$, and the major fragment peaks of the mass spectrum were $m / z=199,181,152$ and 77 . These fragments coincided with that of triphenylsilanol $[\mathrm{FW}=276]$. In the similar method, the main volatile compound ( $\mathrm{ca}$. $80 \mathrm{wt} \%$ ) from 1b was determined as biphenyl. Triphenysilanol was also detected slightly during the melt polycondensation at $350{ }^{\circ} \mathrm{C}$ and $400^{\circ} \mathrm{C}$. These results indicated that the thermal decomposition of the monomers and/or the produced oligomers occurred simultaneously when the condensation reaction of the silanols took place. The ${ }^{13} \mathrm{C}$ CP-MAS NMR spectra of $\mathbf{3 b}, \mathbf{5 b}$ and polyBS were shown in Figure 7. Two broad peaks and a shoulder peak were observed at around 127, 135 and $130 \mathrm{ppm}$ in those of $\mathbf{3 b}$ and $\mathbf{5 b}$, and these peaks coincided with those of polyBS. The small and broad peak, which was not observed in the spectra of polyBS, was also observed at around 140$142 \mathrm{ppm}$ in the spectra of $\mathbf{3} \mathbf{b}$ and $\mathbf{5} \mathbf{b}$. The peak intensity of $\mathbf{5 b}$ was larger than that of $\mathbf{3 b}$. Kapoor et al. ${ }^{21}$ exhibited the ${ }^{13} \mathrm{C}$ CP-MAS spectrum of the 1,3 disubstituted benzene by silicon atoms, and the peak of a carbon in the ortho-position was observed at around $140 \mathrm{ppm}$. Therefore, the peak at around 140$142 \mathrm{ppm}$ would suggest that the 1,3 di-substituted benzene by silicon atoms was produced. 1,4 and 1,2 di-substituted benzene by silicon atoms would be produced in the melt polycondensation process. However, the peaks of them could not be identified because these would be contained in the two broad peaks.
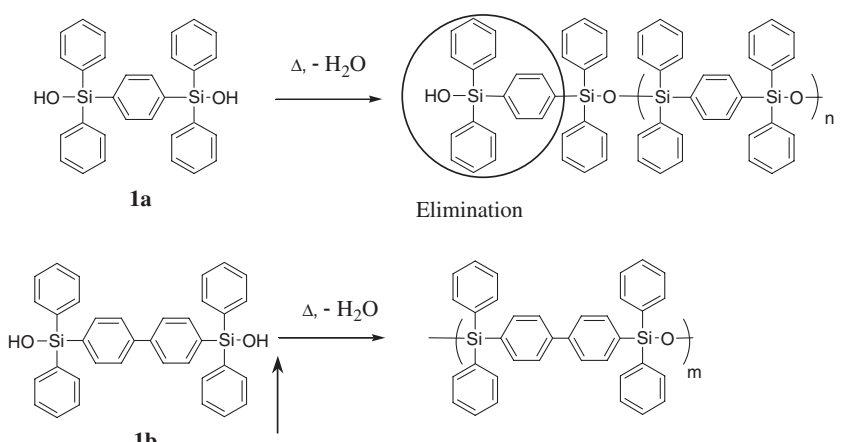

$1 b$

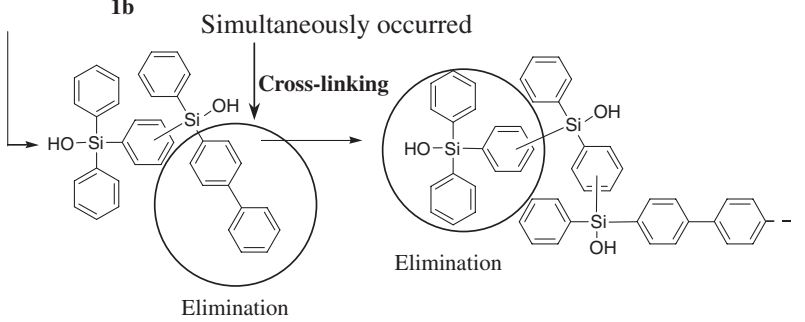

Figure 8. The mechanism of the melt polycondensation.

On the other hand, the peak at around 140-142 ppm was not observed in the spectra of 3a and 5a.

From these results, the mechanism of the melt polycondensation was the process as shown in Figure 8. In the melt polycondensation process of $\mathbf{1 a}$, the elimination of triphenylsilanol from the monomers and/or the chain end of the oligomers occurred simultaneously with the condensation reaction of the silanols. In the case of $\mathbf{1 b}$, the cross-linking reaction resulted from the elimination of biphenyl also took place differently from the process of 1a, considering the di-substituted benzene by silicon atoms was produced and triphenylsilanol was detected by the GC-MS. This cross-linking reaction proceeded considerably in the melt condensation process of $\mathbf{5 b}$ compared with that of $\mathbf{3 b}$.

The thermal decomposition of the monomers and/ or the oligomers would cause the decrease of the crystallinity of 4 (a, b), and made 5 (a, b) amorphous polymers as shown in Figure 3. The cross-linking reaction restricted the polymer chain motion and improved the thermomechanical stability of $\mathbf{5 b}$. It was revealed that the melt polycondensation and the simultaneous cross-linking reaction of $\mathbf{b}$-series were effective to obtain the polysilarylenesiloxane which has a high thermal stability and a high thermomechanical stability.

\section{CONCLUSIONS}

The melt polycondensation of the two kinds of the bis(hydroxydiphenylsilyl)arylene monomers, 1,4-bis(hydroxydiphenylsilyl)benzene and 4,4'-bis(hydroxydiphenylsilyl)biphenyl, was investigated in order to improve the preparation of the fully aromatic polysilarylenesiloxanes which exhibited the high thermal 
stability and the high melting point. The thermal properties of the obtained polymers were investigated by using a TGA, a DSC and a TMA. The IR spectra and the XRD patterns of the polymers indicated that the melt polycondensation occurred in the temperature range from $290^{\circ} \mathrm{C}$ to $400^{\circ} \mathrm{C}$. According to the TGA measurements, the polymers, which were synthesized via the melt polycondensation of each monomer at $350^{\circ} \mathrm{C}$ and $400^{\circ} \mathrm{C}$, exhibited the high thermal stability, and their $T_{\mathrm{d} 5}$ 's were around or over $500^{\circ} \mathrm{C}$. It was revealed that the high heat-resistant films could be synthesized by the convenient procedure.

On the other hand, the polymer main chain structure had an influence on the thermal properties of the polymers. The thermomechanical stability of the polymers containing a biphenylene moiety in the main chain was improved when the melt polycondensation occurred at $400^{\circ} \mathrm{C}$. From the analysis of the volatile compounds generated during the melt polycondensation of 4,4'-bis(hydroxydiphenylsilyl)biphenyl by using a GC-MS, the main volatile compound was determined as biphenyl, and the triphenylsilanol was contained slightly. The ${ }^{13} \mathrm{C}$ CP-MAS NMR spectrum of $\mathbf{5 b}$ indicated that the di-substituted benzene by silicon atoms was produced. These results showed that the cross-linking reaction occurred simultaneously during the condensation reaction of the silanols.

Finally, it was revealed that the melt polycondensation and simultaneous cross-linking reaction were effective to obtain the polysilarylenesiloxane which had high thermal degradation temperature and high thermomechanical stability. This convenient procedure is a promising method to apply the fully aromatic polysilarylenesiloxanes as new candidates for heatresistant materials.

Acknowledgment. We sincerely appreciated to Associate Professor, Dr. Nobukatsu Nemoto, Faculty of Engineering, Nihon University, for very useful discussion with him.

\section{REFERENCES}

1. R. L. Merker and M. J. Scott, J. Polym. Sci., A, 2, 15 (1964).

2. N. Okui, H. M. Li, and J. H. Magill, Polymer, 19, 411 (1978).

3. M. Ikeda, T. Nakamura, Y. Nagase, K. Ikeda, and Y. Sekine, J. Polym. Sci., Polym. Chem. Ed., 19, 2595 (1981).

4. R. L. Merker, M. J. Scott, and G. G. Haberland, J. Polym. Sci., A, 2, 31 (1964).

5. W. R. Dunnavant, Inorg. Macromol. Rev., 1, 165 (1971).

6. J. M. Funt, R. D. Parekh, J. H. Magill, and Y. T. Shah, J. Polym. Sci., Polym. Chem. Ed., 13, 2181 (1975).

7. C. U. Pittman. Jr, W. J. Patterson, and S. P. Mcmanus, J. Polym. Sci., Polym. Chem. Ed., 14, 1715 (1976).

8. P. R. Dvornic and R. W. Lenz, J. Polym. Sci., Polym. Chem. Ed., 20, 951 (1982).

9. Y. Nagase, T. Masubuchi, K. Ikeda, and Y. Sekine, Polymer, 22, 1607 (1981).

10. Y. Nagase, K. Ikeda, and Y. Sekine, Polymer, 23, 1646 (1982).

11. Y. Nagase, T. Nakamura, A. Misawa, K. Ikeda, and Y. Sekine, Polymer, 24, 457 (1983).

12. Y. Nagase, T. Fukatsu, K. Ikeda, and Y. Sekine, Polymer, 24, 463 (1983).

13. L. W. Breed, R. L. Elliott, and M. E. Whitehead, J. Polym. Sci., A-1, 5, 2745 (1967).

14. R. E. Burks Jr, E. R. Covington, M. V. Jackson, and J. E. Curry, J. Polym. Sci., Polym. Chem. Ed., 11, 319 (1973).

15. P. R. Dvronic and R. W. Lenz, Polymer, 24, 763 (1983).

16. H. D. Zhu, S. W. Kantor, and W. J. MacKnight, Macromolecules, 31, 850 (1998).

17. P. R. Dvronic, H. J. Perpall, P. C. Uden, and R. W. Lenz, J. Polym. Sci., Polym. Chem. Ed., 27, 3503 (1989).

18. P. R. Dvornic and R. W. Lenz, Macromolecules, 25, 3769 (1992).

19. H. Ito, E. Akiyama, Y. Nagase, A. Yamamoto, and S. Fukui, Polym. J., 38, 109 (2006).

20. H. N. Beck and R. G. Chaffee, J. Chem. Eng. Data, 8, 602 (1963).

21. M. P. Kapoor, Q. Yang, and S. Inagaki, Chem. Mater., 16, 1209 (2004). 